\title{
Arsenic: the largest mass poisoning of a population in history
}

In this Feature by P Sen and T Biswas, the section "Magnitude of the problem" has a numerical error (BMJ 2013;346:f3625, doi:10.1136/bmj.f3625). The first sentence in the fourth paragraph should have read: "A 2009 press release from the union government reported that 16.654 million (not "16 654 million") people in 79 blocks in eight districts of West Bengal are at risk of exposure to groundwater contaminated with arsenic."

Cite this as: BMJ 2013;346:f3732

๑ B BMJ Publishing Group Ltd 2013 